\title{
A SIMPLIFIED METHOD TO SELECT COMBINED ENERGY SYSTEMS
}

\author{
SÉRGIO TADEU ${ }^{1,2,3}$, MÁRCIO GONÇALVES ${ }^{1,2}$, NUNO SIMÕES $^{1,2} \&$ ANTÓNIO TADEU $^{1,2}$ \\ ${ }^{1}$ Itecons - Institute for Research and Technological Development in Construction, Energy, Environment and \\ Sustainability, Portugal. \\ ${ }^{2}$ ADAI - LAETA, Department of Civil Engineering, FCTUC, University of Coimbra, Coimbra. \\ ${ }^{3}$ Department of Civil Engineering Construction (PCC) - Escola Politécnica, University of São Paulo, Brazil.
}

\begin{abstract}
The European Union aims to ensure that investment in energy efficiency measures is cost-effective. Thus, the minimum energy performance requirements of buildings must follow the so-called cost-optimal levels.

It is known that the impact of a specific measure on the energy performance is affected by others measures when implemented simultaneously, influencing its profitability. For this reason, the profitability of a given package of measures cannot result from the simple sum of potential benefits of each measure. Consequently, to define a cost-optimal solution it is needed to run a great amount of combinations, implying an expensive computational effort.

In order to help with the selection of the energy systems, this work proposes a simplified method for selecting heating and domestic hot water systems as a function of the following variables: initial investment, maintenance cost, energy needs and cost, and efficiency of energy systems.

The proposed method is user-friendly and can assist various stakeholders: policy makers, energy experts, suppliers of products and services and building owners.

Keywords: Cost-optimal, energy retrofit, buildings, sustainability.
\end{abstract}

\section{INTRODUCTION}

The cost-optimal methodology involves a balance between costs and energy savings throughout the lifecycle of a new building or in retrofitting work. The cost-optimal framework to be followed by the Member States was published in EU Delegated Regulation 244/2012 [1] and it is based on EN 15459 [2].

The global cost-optimum is not equal to the sum of cost-optimal solutions for each of those energy measures, and this generates the optimization problem, that is, the search for the cost-optimal solution among a great number of combinations. While computationallyexpensive cost-optimal problems are being addressed with the aforementioned complex techniques, the present work provides a way to reduce the complexity of cost-optimality problems.

In the next section, a simplified method for comparing energy systems' configuration is presented to evaluate their economic performance. Section 3 details the reference building and the parameters that constitute the calculation framework. The methodology is applied in Section 4. Finally, the conclusions are presented in Section 5.

\section{SIMPLIFIED METHOD TO EVALUATE THE OPTIMAL CONFIGURATION OF THE ENERGY SYSTEMS}

In the present study, apart from the basic economic parameters, the variables involved in the calculation were the initial investment, energy cost, efficiency of heating and domestic hot water (DHW) systems and useful energy needs. To bring the framework to the user's point of view, the global cost was calculated as a function of the useful energy needs. 
In the case of Portugal, the energy used by the Portuguese residential sector for cooling was only $0.5 \%$ in 2010 [3], and therefore the energy needs have been restricted to heating and DHW services.

The simplified method presented in this section is based on useful energy needs. The starting point is the following formula for the total cost $G C$ of a set number of measures $N M$, calculated from the financial perspective as a net present value over the period $\tau$ years:

$$
G C=\sum_{j=1}^{N M}\left[I_{j}+\sum_{i=1}^{\tau}\left(C_{j, i} \cdot D_{\tau}\right)-\left(V_{\tau, j} \cdot D_{\tau}\right)\right]
$$

in which $j$ is the measure (energy system set) being analysed; $I_{j}$ is the investment cost; $C_{j, i}$ represents the annual cost, which is subjected to the discount factor $D_{\tau} ; V_{\tau, j}$ is the residual value associated with each measure, calculated at the end of the period by applying the discount factor $D_{\tau}$.

A life cycle of 20 years was considered in this study, since, according to EN 15459, this is the life span assumed for most of the energy systems under study.

Next, the global cost is calculated for the energy measure consisting of installing a new energy system or a set of them. The first indicator to be analysed is the total cost associated with useful energy needs of a DHW system. Taking into account the aforementioned assumptions, the global cost for the DHW system $w, k$ can be expressed as follows:

$$
G C_{w, k}=I_{w, k}+\sum_{i=0}^{\tau}\left(M_{w, k, i}+E C_{w, k, i}\right) D_{r}
$$

where $M_{w, k, i}$ is the maintenance cost in the year $i, E C_{w, k, i}$ comprises the energy cost in the year $i$, which depend on the annual final energy use $F E_{\mathrm{w}, k}$ and the energy price $C_{e n, w, k, i}$ :

$$
E C_{w, k, i}=F E_{w, k} C_{e n, w, k, i}
$$

And if DHW is again provided by a single system $(k=1)$, eqn. (2) becomes:

$$
G C_{w, 1}=I_{w, 1}+\sum_{i=0}^{\tau}\left(M_{w, 1, i}+C_{e n, w, 1, i} \frac{1}{\eta_{w, 1}} E_{w}\right) D_{r}
$$

where $\eta_{w, 1}$ is the nominal efficiency of the system. Thus, the total cost turns into a linear function of the useful energy needs $E_{w}$ :

$$
G C_{w, 1}=\mathrm{b}_{1}+\mathrm{b}_{2} E_{w}(€)
$$

where $\mathrm{b}_{1}=I_{w, 1}+\sum_{i=0}^{\tau} M_{w, 1, i} D_{r}$ and $\mathrm{b}_{2}=\sum_{i=0}^{\tau}\left(C_{e n, w, 1, i} \frac{1}{\eta_{w, 1}} D_{r}\right)$.

Similarly, the total cost for a heating system can be expressed as:

$$
G C_{h, 1}=\mathrm{c}_{1}+\mathrm{c}_{2} E_{h}(€)
$$


where $\mathrm{c}_{1}=I_{h, 1}+\sum_{i=0}^{\tau} M_{h, 1, i} D_{r}$ and $\mathrm{c}_{2}=\sum_{i=0}^{\tau}\left(C_{e n, h, 1, i} \frac{1}{\eta_{h, 1}} D_{r}\right)$

Replacing both energy systems, combining eqns. (5) and (6) leads to

$$
G C=\mathrm{b}_{1}+\mathrm{c}_{1}+\mathrm{b}_{2} E_{w}+\mathrm{c}_{2} E_{h}(€)
$$

As before, if it is assumed that the useful energy needs $(E)$ are at first only associated with DHW, this equation becomes

$$
G C=\left(b_{1}+c_{1}\right)+b_{2} E \quad(€)
$$

In this equation it is assumed that the initial investment and maintenance cost are related to both systems, as they are accountable even if not used. Then, once DHW needs are covered, they remain constant and subsequent increases in useful energy needs are assigned to heating. This leads to the following equation:

$$
G C=\left(b_{1}+c_{1}+\left(b_{2}-c_{2}\right) E_{w}\right)+c_{2} E(€)
$$

It is observed that the energy system used for heating affects the global cost, even when only DHW is consuming energy. Equations 8 and 9 and their use are illustrated in Figure 1. In this hypothetical example, energy system 2 turns out to be more economically attractive for the energy needs specified in the retrofitting project. In conclusion, energy system 2 would be the most economically attractive energy system in the range of useful energy demand defined by the intersection points of Figure 1. With the DHW needs kept constant, modifying the heating demand shown in the Fig. 1 would improve one of the objective functions at the cost of worsening the other objective function.

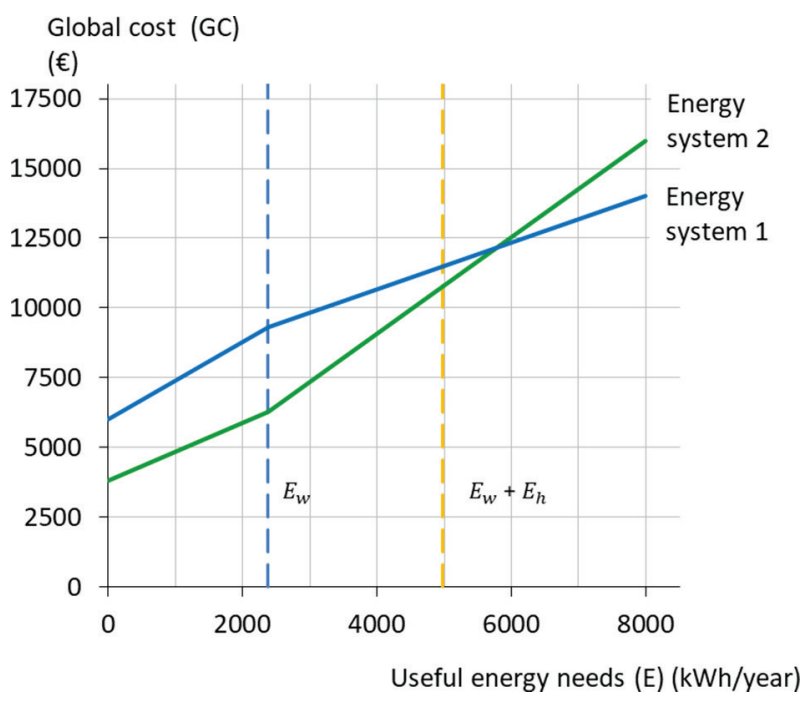

Figure 1: Economic evaluation of energy systems. 


\section{CASE STUDY}

\subsection{Definition of the reference building}

A typical residential building, constructed between 1960 and 1990, consists of a single storey 3-bedroom house with masonry walls, located in Portugal. Rooms would be heated by electric heaters, whose nominal efficiency is $100 \%$, while a gas heater with an average efficiency of $60 \%$ would be used for DHW [4], [5].

Walls would be made of masonry. The glazed area was assumed to be distributed equally between the four directions of the facades (north, south, east and west). Shading devices were assumed to be light coloured curtains made of a thin fabric that would have an obstruction factor of 0.38 . It was also found that the thermal inertia corresponds to an intermediate class of the energy storage capacity [3], [6].

\subsection{Energy needs of the reference scenario}

The Portuguese regulation uses the seasonal method [3] described in EN ISO 13790 [7] to estimate the energy needs for residential units. The calculation method was adapted from [8]:

$$
E_{h}=Q_{t r}+Q_{v e}-Q_{\text {gain }}(\mathrm{kWh} / \text { year })
$$

where,

$Q_{t r}$ is the transmission heat transfer coefficient;

$Q_{v e}$ is the heat transfer coefficient by ventilation;

$Q_{\text {gain }}$ is the net heat gain.

The nominal needs of useful energy for DHW indicated by the Portuguese regulation [6] are calculated using the following formula:

$$
E_{w}=\frac{M 4187 \Delta T n_{d}}{3600000}(\mathrm{kWh} / \text { year })
$$

where $\Delta T$ is the temperature gap necessary for DHW supplies and the value of $35^{\circ} \mathrm{C}$ was established; $n_{d}$ is the annual number of days with consumption, assumed to be 365 days; and $M$ is the average daily DHW consumption, which depends on the conventional number of occupants. In this reference scenario, four persons were considered to be living in the dwelling. Thus, $M$ results in 160 litres and $E_{w} 2377.3 \mathrm{kWh} /$ year. This value is quite close to real consumption at national level [3].

\subsection{Definition of the energy systems considered}

The characteristics of combined heating and DHW systems proposed in this study are listed in Table 1. Investment costs are shown in Table 2. To perform the economic evaluation of DHW and heating separately when the system provides both services (sets 3 and 4), the investment in energy system equipment was assumed to be proportional to the DHW and heating energy needs $\left(E_{w}\right.$ and $\left.E_{h}\right)$. 
Table 1: Characteristics of the configuration of each energy system set.

\begin{tabular}{ccccc}
\hline & DHW system & $\eta_{w, 1}$ & Heating system & $\eta_{h, 1}$ \\
\hline Set 1 & Gas water heater (GWH) & 0.60 & Electric heater (EE) & 1.00 \\
Set 2 & Gas water heater (GWH) & 0.78 & Heat pump (HP) & 4.30 \\
Set 3 & Gas boiler (GB) & 0.83 & Gas boiler (GB) & 0.93 \\
Set 4 & Biomass boiler (BB) & 0.92 & Biomass boiler (BB) & 0.92 \\
\hline
\end{tabular}

Table 2: Investment and energy cost (VAT and taxes included) for the configuration of each energy system

\begin{tabular}{ccccccc}
\hline & $\begin{array}{c}\text { DHW } \\
\text { system }\end{array}$ & $\begin{array}{c}\text { Investment } \\
I_{w, 1}(\boldsymbol{\epsilon})\end{array}$ & $\begin{array}{c}\text { Energy cost } \\
C_{e n, w, 1, i}(\boldsymbol{(} / \mathbf{k W h})\end{array}$ & $\begin{array}{c}\text { Heating } \\
\text { system }\end{array}$ & $\begin{array}{c}\text { Investment } \\
I_{h, 1}(\boldsymbol{\epsilon})\end{array}$ & $\begin{array}{c}\text { Energy cost } \\
C_{e n, h, 1, i}(\boldsymbol{\epsilon} / \mathbf{k W h})\end{array}$ \\
\hline Set 1 & $\mathrm{GWH}$ & 457.7 & 0.1032 & $\mathrm{EE}$ & 1189.8 & 0.230 \\
Set 2 & $\mathrm{GWH}$ & 534.7 & 0.1032 & $\mathrm{HP}$ & 6034.1 & 0.230 \\
Set 3 & $\mathrm{GB}^{1}$ & 1058.5 & 0.1032 & $\mathrm{~GB}^{1}$ & 1101.8 & 0.077 \\
Set 4 & $\mathrm{BB}^{1}$ & 3819.0 & 0.0492 & $\mathrm{BB}^{1}$ & 4010.0 & 0.045 \\
\hline
\end{tabular}

${ }^{1}$ The investment cost was shared between heating (51\%) and DHW (49\%), as set in the baseline scenario (2377 over $4832 \mathrm{kWh} /$ year). For the other scenarios, the share was modified appropriately.

\subsection{Financial data}

A cost optimality study depends on the price trend of energy. The EU has published the energy price trends until 2050 [9]. Initial energy cost is obtained from Portugal's Energy Regulator, ERSE [10]. The discount rate was assumed to be $5 \%$ for financial perspective. For replacement cost, a lifespan of 50 years was assumed for insulation, 40 years for windows and 20 years for mechanical systems. In the analysis, the maintenance cost is assumed to be $1 \%$ of the initial investment, in accordance with the predominant values indicated in EN 15459 [2].

\section{RESULTS AND DISCUSSION}

\subsection{Global cost - DHW system}

The result of the different energy system configurations is shown in Figure 2. The linear equation for each energy system (eqn. 5) is obtained by using in eqn. 4 the given economic parameters.

For each useful energy need, the cost-optimal system is identified by the segments that minimize the global cost before and after the intersection point $I P$ (at $E=441.8 \mathrm{kWh} /$ year). It can be seen that for the reference occupancy of four users, the efficiency and initial cost of a GWH would be critical to it becoming the least or the most cost-efficient solution. Even if only one user were living in the dwelling, the highly efficient GWH would be the cost-optimal solution, 


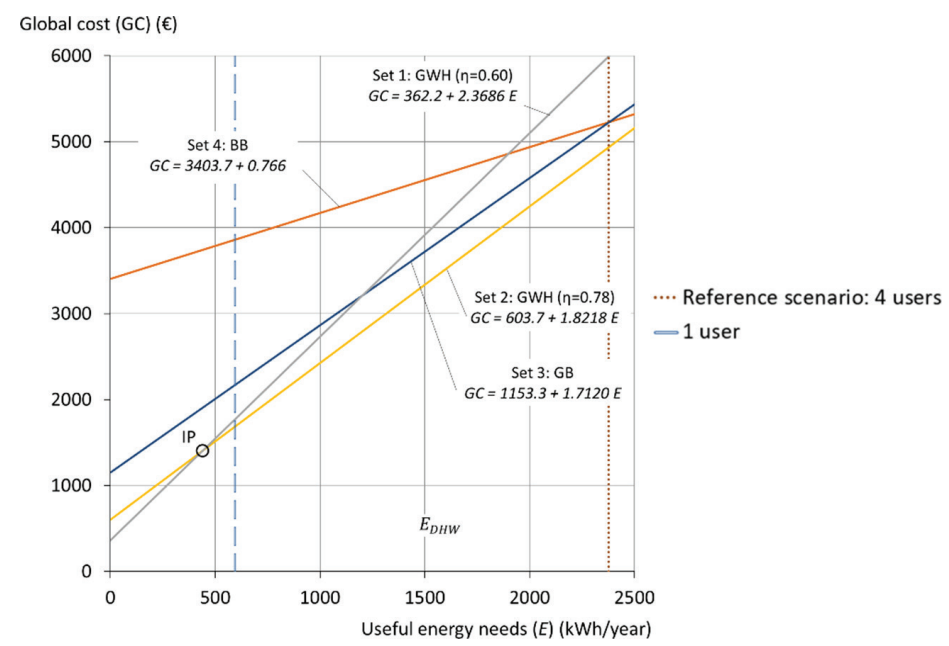

Figure 2: Economic evaluation of energy systems used for DHW and with no heating retrofitting.

since in that case $E_{w}=594.3 \mathrm{kWh} /$ year, which is bigger than the useful energy need corresponding to the $I P$. If there is a change in the occupancy profile, then the cost-efficient energy system would change only if the updated DHW needs changed until they passed the useful energy needs of any intersection point.

\subsection{Global cost - Heating system}

When the heating system is analysed alone, the global cost is calculated through the same parameters used in the previous section, but through equation 6 . The results can be compared in Figure 3. GB is the most cost-efficient system for a broad range of deviation from the

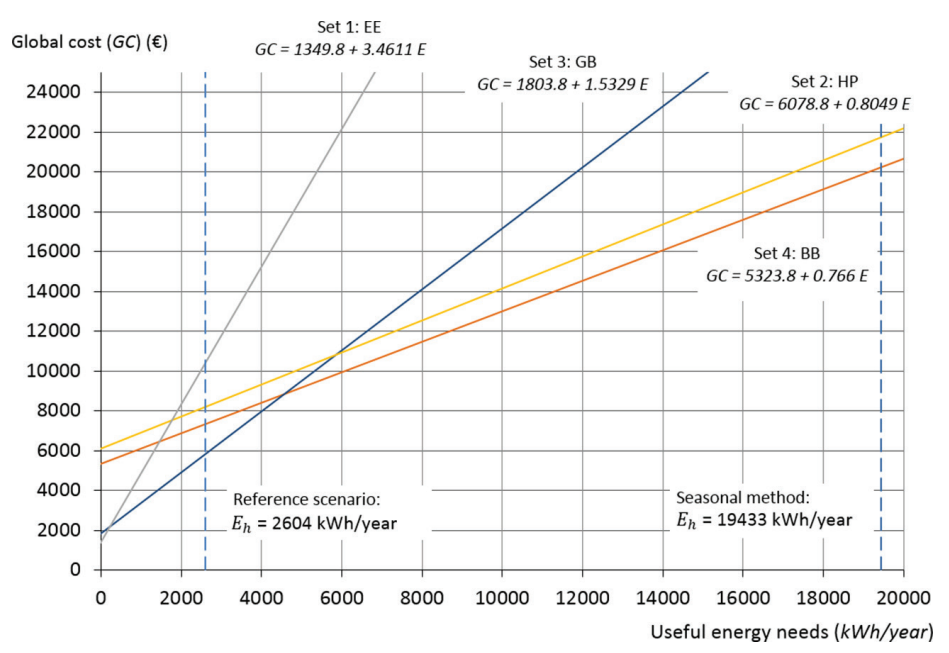

Figure 3: Economic evaluation of energy systems used for heating, and with no DHW retrofitting. 
heating demand calculated for the reference scenario. Even though HP and BB are more energy-efficient, the high investment they require removes their economic attractiveness.

The large gap between real energy consumption (reference scenario: $E_{h}=2604 \mathrm{kWh} /$ year) and estimated energy consumption according the Portuguese regulation (seasonal method: $E_{w}=19433 \mathrm{kWh} /$ year , can have a very negative economic impact on the promoter of the renovation. If the seasonal method were followed, then the optimal energy system would be $\mathrm{BB}$. This system has a greater investment than GB and, moreover, the energy savings over the years would be lower than expected, so that the real total cost of BB would be overestimated.

\subsection{Global cost - DHW and heating systems}

The global cost calculated for the reference scenario in the general case, when both DHW and heating services are required, is detailed in Table 3. These linear equations correspond to equations 8 and 9. The useful energy needs of the scenario are $4981.0 \mathrm{kWh} /$ year, which

Table 3: Linear equations of global cost (GC) in $€$ for the energy systems considered.

\begin{tabular}{ccc}
\hline & $0 \leq E \leq E_{w}$ & $E>E_{w}$ \\
\hline Set 1 & $G C=1712.0+2.3683 E$ & $G C=-885.7+3.4611 E$ \\
Set 2 & $G C=6682.4+1.8217 E$ & $G C=9099.5+0.8049 E$ \\
Set 3 & $G C=2957.1+1.7120 E$ & $G C=3382.9+1.5323 E$ \\
Set 4 & $G C=8727.5+0.7660 E$ \\
\hline
\end{tabular}

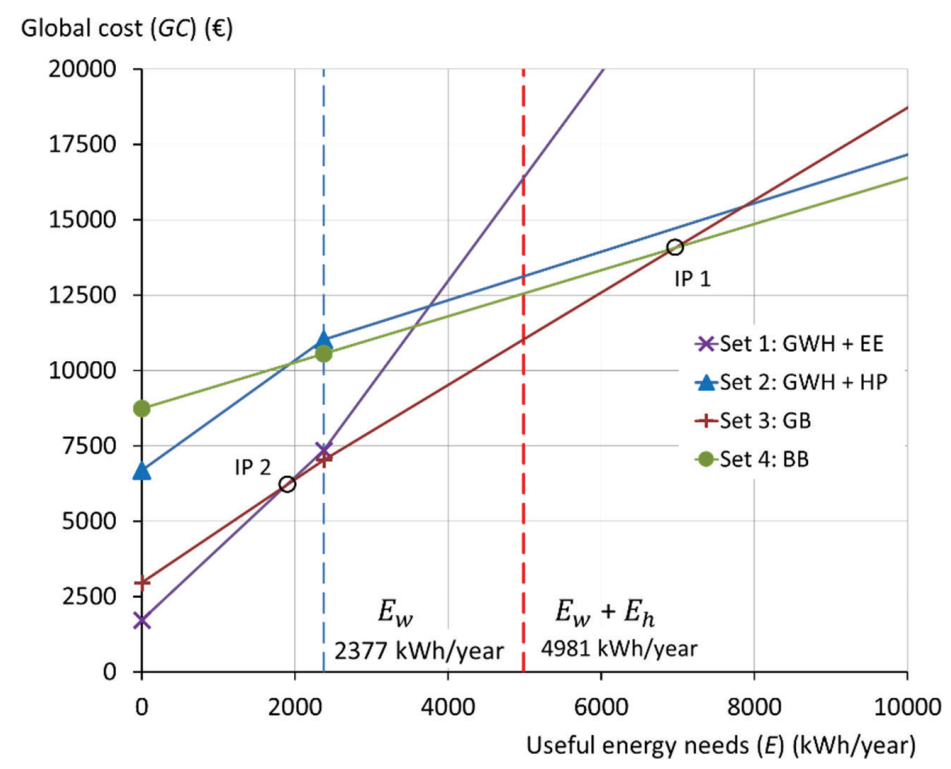

Figure 4: Global cost of energy systems retrofitting. 
includes DHW and heating, as shown in the Fig. 4. It is concluded that, when the heating service begins to consume energy, GB is the most cost-effective solution until $=6969.2 \mathrm{kWh} /$ year (IP1), with heating accounting for $4592.2 \mathrm{kWh} /$ year. Above this value, the biomass boiler would have the lowest global cost among the other alternatives. GB would be still the optimal solution if only DHW were demanded since the useful energy needs corresponding to IP 2 are lower than DHW needs.

\section{CONCLUSIONS}

In this paper, a simplified method to identify the optimal energy systems of residential buildings has been proposed, in terms of global cost. This method can be used to estimate the most economically attractive retrofitting solutions.

Taking the dominance of energy systems into account, the cost-optimal package could be estimated by adding the cost-optimal insulation measures to the cost-optimal energy system configuration identified by the simplified method. The simplified calculations described in the present work make it possible to pinpoint the most convenient energy measures in the detached houses. Although this simplified method has been applied in this work to a representative dwelling of the Portuguese building stock, it is equally applicable to different types of buildings, including non-residential buildings, and buildings in other climatic regions. It is also possible to aggregate energy needs for cooling, which was not considered in this work.

\section{ACKNOWLEDGEMENTS}

Sérgio Tadeu is grateful for the financial support provided by the Fundação de Amparo à Pesquisa do Estado de São Paulo - FAPESP, through grant PIPE - 2016/00880-9 (Brazil). Márcio Gonçalves is grateful for the support by the doctoral FCT grant PD/BD/135194/2017. This work was framed within the project Expert A+ (POCI-01-0246-FEDER-026751) funded by Portugal 2020 through the COMPETE 2020 programme.

\section{REFERENCES}

[1] European Commission, Commission Delegated Regulation (EU) No 244/2012 of 16 January 2012 supplementing Directive 2010/31/EU of the European Parliament and of the Council on the energy performance of buildings by establishing a comparative methodology framework for calculating. Official Journal of the European Union, L 81/18-36, 2012.

[2] EN 15459-Energy performance of buildings-Economic evaluation method for energy systems in buildings. European Committee of Standardisation, Bruxels, 2007.

[3] Instituto Nacional de Estatística (INE) and DGEG. Inquérito ao Consumo de Energia no Sector Doméstico 2010, 2010.

[4] Serra, C., Simões, N., Tadeu, S. \& Tadeu, A., Definition of Reference Buildings for Energy Performance Calculation-Portuguese Case, Energy for Sustainability 2013, Coimbra, Portugal, 2013.

[5] Tadeu, S., Tadeu, A., Simões, N., Gonçalves, M. \& Prado, R., A sensitivity analysis of a cost optimality study on the energy retrofit of a single-family reference building in Portugal. Energy Efficiency, 11(6), pp. 1411-1432, 2018. https://doi.org/10.1007/ s12053-018-9645-5

[6] Ministério do Ambiente, Ordenamento do Território e Energia. Despacho n. ${ }^{\circ} 15793-$ E/2013. Diário da Repúplica, (14), pp. 14-25, 2013.

[7] ISO EN 13790-Energy performance of buildings-Calculations of energy use for space heating and cooling. 2008. 
[8] Diário da República, ${ }^{\circ}$ 15793-I/20013 (extrato), 2. ${ }^{\text {a }}$ série — N. ${ }^{\circ} 234$ - 3 de dezembro de 2013. 2013.

[9] European Commission, EU Energy, Transport and GHG Emissions: Trends to 2050, Reference Scenario 2013. 2013.

[10] Energy Services Regulatory Authority. Reference Prices in the Liberalized Market of Electricity and Natural Gas in Continental Portugal (in Portuguese), 2017. 